\title{
Synthesis and Evaluation of Some Novel Semicarbazones Based Benzimidazole Derivatives as Anticonvulsant Agent
}

\author{
H. Rajak
}

\begin{abstract}
The use of current antiepileptic drugs has been questioned due to their non selectivity and undesirable side effects. In pursuit of better anticonvulsant drug and the significance of semicarbazones as anticonvulsant pharmacophore, a series of novel benzimidazole substituted semicarbazones were designed, synthesized and evaluated for their anticonvulsant activity. Semicarbazones based benzimidazole analogues are hitherto unreported for their promising anticonvulsant activity. The synthesized molecules were characterized using elemental and spectral (IR, ${ }^{1} \mathrm{H}$ NMR, ${ }^{13} \mathrm{C}$ NMR and MS) analysis. The anticonvulsant activities of the compounds were investigated using maximal electroshock seizure (MES) model. The rotarod test was employed for neurotoxicity evaluation. Efforts were also made to establish structure-activity relationships among synthesized compounds. The results of these investigations confirmed that the pharmacophore model with four binding sites is vital for antiepileptic activity.
\end{abstract}

Index Terms-A semicarbazones, benzimidazole, anticonvulsant activity.

\section{INTRODUCTION}

Epilepsy is not a disease, but a syndrome of different cerebral disorders of central nervous system distinguished by the periodic sudden loss or impairment of consciousness, frequently followed by convulsions. About 50 million people worldwide have epilepsy, making this condition the second leading neurological disorder with almost $90 \%$ of these people being in developing countries. Epilepsy also affects about $4 \%$ of individuals over their lifetime [1]. Around $70 \%$ of epileptic patients may be provided with adequate seizure controls with the help of conventional antiepileptic drugs such as phenobarbitone, phenytoin, carbamazepine, ethosuximide, valproate, benzodiazepine, but shows unfavorable adverse effects such as drowsiness, ataxia, gastrointestinal disturbances, hepatotoxicity, megaloblastic anaemia and sometimes even life threatening conditions [2]. Thus, there is a vast requirement for the development of more effective and safer anticonvulsant drugs.

In the recent years, aryl semicarbazones has been recognized as structurally novel class of compounds with remarkable antiepileptic activity [3]-[5]. The conformational studies of the existing anticonvulsant drugs such as phenytoin, carbamazepine, lamotrigine, rufinamide and phenobarbitone

Manuscript received April 10, 2014; revised July 8, 2014.

Harish Rajak is with SLT Institute of Pharmaceutical Sciences, Guru Ghasidas University, Bilaspur 495009, (C.G.) India (e-mail: harishdops@yahoo.co.in). has led to the proposal of a model for anticonvulsant activity [6] (Fig. 1). This semicarbazones based pharmacophore model comprises of the four essential binding sites as follows: (i) An aryl hydrophobic binding site (A) with halo substituent, preferably at para position; (ii) A hydrogen bonding domain (HBD); (iii) An electron donor group (D) and (iv) Another hydrophobic-hydrophilic site controlling the pharmacokinetic properties of the anticonvulsant (C) (Fig. 2). In earlier pharmacophore model studies, our research group confirmed that the presence of aryl group (preferably halogen substituted) near the semicarbazone moiety is one of the important parameters for anticonvulsant activity [7]. The effect of adding benzimidazole nucleus to semicarbazone based pharmacophoric model for anticonvulsant activity has not been observed till now.

\section{MATERIALS AND METHODS}

All the chemicals and solvents used in this study were procured from E-Merck (Darmstadt, Germany), Aldrich (Steinheim, Germany) and Himedia (Mumbai, India). Melting points were determined by open capillary method and are uncorrected. Elemental analysis was performed using an elemental analyzer Heraeus Carlo Erba-1108, IR spectra were recorded on a Perkin Elmer IR spectrophotometer ( $\mathrm{KBr}$ disc) (Perkin Elmer, Beaconsfield, UK), NMR spectra on a Bruker DRX-300 NMR spectrometer (DMSO- $d_{6}$, TMS) (Bruker Bioscience, Billerica, MA, USA) and the electrospray mass spectra on a Micromass Quattro II triple-quadrupole mass spectrometer (Methanol) (Micromass, Manchester, UK).

The title compounds were prepared using the synthetic strategy described in scheme 1 . The first step of synthetic route comprises of preparation of Imesatin (III) by reaction of isatin (I) with para-phenylenediamine (II) in the presence of ethanol. 1-(-4-(2-oxoindolin-3-ylideneamino)phenyl) urea (IV) was prepared from reaction of imesatin (III) with sodium cyanate in the presence of glacial acetic acid. The reaction of (IV) with hydrazine hydrate in the presence of ethanol resulted in the synthesis of 4(-4-\{2-oxoindolin-3-ylideneamino $\}$ phenyl)semicarbazide $(\mathrm{V})$. Title compounds [VI(a-j)] were prepared by reaction of the appropriate carbonyl compounds with (V) (Table I).

\section{A. General Procedure for Synthesis of Imesatin (III)}

The equimolar quantities $(0.01 \mathrm{~mol})$ of isatin and $p$-phenylenediamine were dissolved in sufficient quantity of methanol $(30 \mathrm{ml})$ in the presence of acetic acid. The reaction mixture was refluxed for $1 \mathrm{~h}$ followed by standing at $\mathrm{rt}$ for $2 \mathrm{~h}$ 
resulted in the formation of crude imesatin. The product was recrystallized with ethanol [8].

TABLE I: PhysicAl PRoPerties OF SUbSTITUTED SEMICARBAZONES

\begin{tabular}{lccl}
\hline Compound & \multicolumn{3}{c}{ Physical Properties } \\
\cline { 2 - 4 } & Yield & m.p. $\left({ }^{\circ} \mathbf{C}\right)$ & $\mathbf{R}_{\mathbf{f}}{ }^{*}$ \\
\hline III & 84.25 & $218-220$ & 0.52 \\
IV & 65.82 & $245-247$ & 0.64 \\
V & 67.87 & $228-230$ & 0.82 \\
{$[\mathrm{VI}(\mathrm{a})]$} & 55.65 & $198-200$ & 0.58 \\
{$[\mathrm{VI}(\mathrm{b})]$} & 66.78 & $160-162$ & 0.73 \\
{$[\mathrm{VI}(\mathrm{c})]$} & 65.12 & $174-176$ & 0.81 \\
{$[\mathrm{VI}(\mathrm{d})]$} & 67.51 & $225-227$ & 0.77 \\
{$[\mathrm{VI}(\mathrm{e})]$} & 79.83 & $178-180$ & 0.72 \\
{$[\mathrm{VI}(\mathrm{f})]$} & 68.64 & $186-187$ & 0.66 \\
{$[\mathrm{VI}(\mathrm{g})]$} & 65.33 & $205-207$ & 0.58 \\
{$[\mathrm{VI}(\mathrm{h})]$} & 67.28 & $155-157$ & 0.62 \\
{$[\mathrm{VI}(\mathrm{i})]$} & 57.81 & $170-172$ & 0.78 \\
{$[\mathrm{VI}(\mathrm{j})]$} & 62.45 & $192-194$ & 0.74 \\
\hline
\end{tabular}

*Solvent system: $\mathrm{CHCl}_{3}: \mathrm{CH}_{3} \mathrm{OH}$ in the ratio $8: 2$

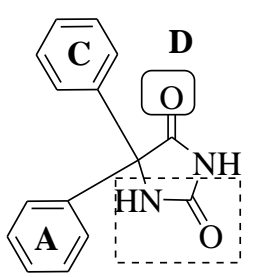

Phenytoin

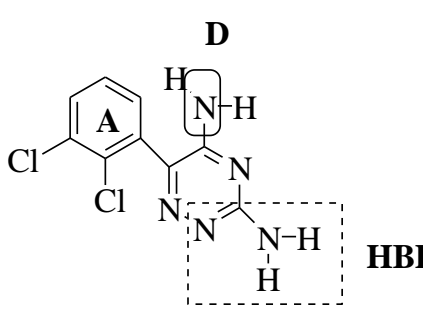

Lamotrigine

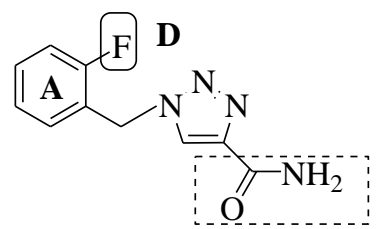

HBD

\section{Rufinamide}

Fig. 1. Commonly used anticonvulsant drugs with their vital structural features. (A) hydrophobic aryl ring system, (HBD) hydrogen binding domain, (D) electron donor moiety and (C) Another hydrophobichydrophilic site

\section{B. General Procedure for Synthesis of}

\section{1-(-4-(2-oxoindolin-3-ylideneamino)phenyl) Urea (IV)}

The appropriate imesatin $(0.01 \mathrm{~mol})$ was dissolved in $10-30 \mathrm{ml}$ of glacial acetic acid diluted to $100 \mathrm{ml}$ with distilled water. An equimolar quantity of sodium cyanate in $20-30 \mathrm{ml}$ warm water was added with stirring. The reaction mixture was allowed to stand for several $\mathrm{h}$ followed on an ice bath, the precipitates obtained were collected by filtration, washed with cold water and were recrystallized from $90 \%$ aqueous ethanol.

\section{General Procedure for Synthesis of}

4(-4-\{2-oxoindolin-3-ylideneamino\}phenyl)semicarbazide (V)
The compound IV $(0.01 \mathrm{~mol})$ was dissolved in $30-40 \mathrm{ml}$ of ethanol. To this was added an equimolar solution of hydrazine hydrate in $5 \mathrm{ml}$ of water. The reaction mixture was made alkaline by adding $4 \mathrm{~g}$ of $\mathrm{NaOH}$ pellets. The contents were then refluxed for $2-8 \mathrm{~h}$ followed by cooling on an ice bath. The product obtained was filtered and recrystallized from $90 \%$ ethanol.

\section{General Procedure for Synthesis of 1-(3-substitutedbenzylidene-4-(4-(2-oxoindoline-3ylidenea mino)phenyl)semicarazinde (VI)}

The equimolar quantity $(0.06 \mathrm{~mol})$ of $\mathbf{V}$ and carbonyl compound were dissolved in $20 \mathrm{ml}$ of ethanol (95\%) and $\mathrm{pH}$ of reaction was adjusted between 4 and 5 using glacial acetic acid. The mixture was reflux for $30 \mathrm{~min}$ to $1 \mathrm{~h}$ and then cooled in an ice bath. The solution was poured on crushed ice to induce crystallization.

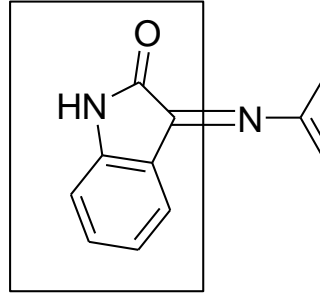

A

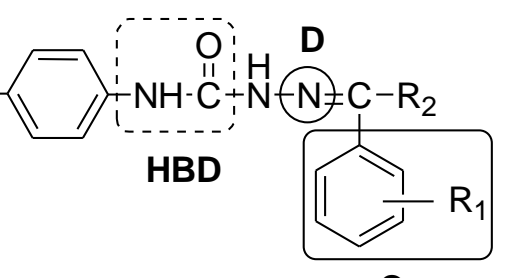

$\mathrm{VI}(\mathrm{a}-\mathrm{j})$
Fig. 2. Pharmacophoric structural features in title compounds: (A) hydrophobic aryl ring system, (HBD) hyrdrogen binding domain, (D) electron donor moiety, (C) Distal aryl ring.

The resulting precipitates were filtered, dried and recrystallized from aqueous ethanol $(95 \%)$.

The structures of the compounds were confirmed on the basis of elemental analysis, IR, ${ }^{1} \mathrm{H}-\mathrm{NMR},{ }^{13} \mathrm{C}-\mathrm{NMR}$ and mass spectroscopy. The results of spectroscopic studies showed data in conformity to the structures of the respective compounds.

The anticonvulsant screening [3], [4], [9] was performed using male albino mice (swiss, 18-25 g). The anticonvulsant activity of the test compounds was evaluated by maximal electroshock seizure (MES) model. The MES test identifies those compounds which stop seizure spread and it is used to evaluate drug effectiveness in tonic-clonic (grand mal) type of epilepsy. Phenytoin was used as the standard drugs for the comparison. Acute neurological toxicity was determined in the rotorod test [3], [4], [9]. Procedures employed for evaluation of anticonvulsant activity and neurotoxicity were reviewed and approved by the University Animal Ethical Committee.

\section{E. MES Test}

The maximal seizure usually consists of a short period of tonic extension of the hind limbs and a final clonic episode. The maximal electroshock seizures were elicited with altering current of $60 \mathrm{~mA}$ intensity delivered for $0.2 \mathrm{~s}$ via ear clip electrodes. The different stages of convulsions are (a) tonic flexion (b) tonic extensor phase (c) clonic convulsion (d) stupor (e) recovery or death. The vanishing of the hind limb tonic extensor component of convulsion was considered as positive criteria. 


\section{F. Neurotoxicity Screening}

Neurotoxicity (minimal motor impairment) was evaluated in mice by the rotorod test. The mice were trained to stopover an accelerating rotorod of diameter $3.2 \mathrm{~cm}$ that rotates at 6 revolutions per min. Only those animals which had proven their competence to remain on the revolving rod for at least 1 min were considered for the test. Previously trained mice were given test compounds i.p. in dose of $50 \mathrm{mg} / \mathrm{kg}$. $30 \mathrm{~min}$ after i.p. administration the mice were placed on the rotating rod. Neurotoxicity was indicated by the failure of the animals to maintain equilibrium on the rod for at least $1 \mathrm{~min}$ in each of the three trials.<smiles>O=C1Nc2ccccc2C1=O</smiles>

I<smiles>Nc1ccc(N)cc1</smiles>

II (a)<smiles>Nc1ccc(/N=C2\C(=O)Nc3ccccc32)cc1</smiles>

III (b)<smiles>NC(=O)Nc1ccc(/N=C2\C(=O)Nc3ccccc32)cc1</smiles>

(c)<smiles>[R]C(=NNC(=O)Nc1ccc(N=C2C(=O)Nc3ccccc32)cc1)c1cccc(Br)c1</smiles>

\begin{tabular}{llllll}
\hline Compound Code & $\mathbf{R}_{\mathbf{1}}$ & $\mathbf{R}$ & Compound Code & $\mathbf{R}_{\mathbf{1}}$ & $\mathbf{R}_{\mathbf{2}}$ \\
& & $\mathbf{2}$ & & & \\
\hline$[\mathrm{VI}(\mathrm{a})]$ & $3-\mathrm{Cl}$ & $\mathrm{H}$ & {$[\mathrm{VI}(\mathrm{f})]$} & $\mathrm{H}$ & $\mathrm{H}$ \\
{$[\mathrm{VI}(\mathrm{b})]$} & $4-\mathrm{Cl}$ & $\mathrm{H}$ & {$[\mathrm{VI}(\mathrm{g})]$} & $4-\mathrm{OH}$ & $\mathrm{H}$ \\
{$[\mathrm{VI}(\mathrm{c})]$} & $2-\mathrm{Cl}$ & $\mathrm{H}$ & {$[\mathrm{VI}(\mathrm{h})]$} & $\mathrm{H}$ & $\mathrm{CH}$ \\
& & & & & 3 \\
{$[\mathrm{VI}(\mathrm{d})]$} & $4-\mathrm{NO}_{2}$ & $\mathrm{H}$ & {$[\mathrm{VI}(\mathrm{i})]$} & $4-\mathrm{CH}_{3}$ & $\mathrm{H}$ \\
{$[\mathrm{VI}(\mathrm{e})]$} & $4-\mathrm{N}\left(\mathrm{CH}_{3}\right)$ & $\mathrm{H}$ & {$[\mathrm{VI}(\mathrm{j})]$} & $4-\mathrm{OCH}$ & $\mathrm{H}$
\end{tabular}

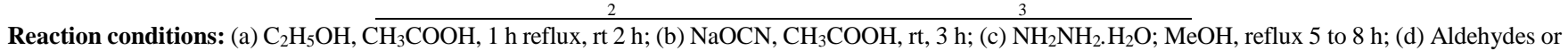
ketone, $\mathrm{CH}_{3} \mathrm{COOH}$, reflux, $30 \mathrm{~min}$ to $1 \mathrm{~h}$.

Scheme 1. Synthesis of semicarbazone derivatives [VI(a-j)].

TABLE II: ANTICONVULSANT ACTIVITY AND NEUROTOXICITY STUDIES ON SYNTHESIZED SEMICARBAZONES

\begin{tabular}{|c|c|c|c|c|c|}
\hline \multirow[t]{3}{*}{ Compound } & \multicolumn{5}{|c|}{ Intraperitoneal injection in mice $^{\mathrm{a}}$} \\
\hline & \multicolumn{2}{|c|}{ MES Screening } & \multicolumn{3}{|c|}{ NT Screening } \\
\hline & Dose & $\begin{array}{l}\text { Duration of tonic hind limb } \\
\text { extension (in sec) } n=6 \text { mean } \pm \text { SD }\end{array}$ & Recovery & Dose & $\begin{array}{l}\text { Means of time (s) spent on } \\
\text { the rod } \pm \text { SD }\end{array}$ \\
\hline$[\mathrm{V}(\mathrm{a})]$ & $50 \mathrm{mg}$ & $11.25 \pm 1.84$ & Yes & $50 \mathrm{mg}$ & $84.5 \pm 26.6$ \\
\hline$[\mathrm{V}(\mathrm{b})]$ & $50 \mathrm{mg}$ & $9.22 \pm 1.73$ & Yes & $50 \mathrm{mg}$ & $110.54 \pm 28.43$ \\
\hline$[\mathrm{V}(\mathrm{c})]$ & $50 \mathrm{mg}$ & $11.02 \pm 1.32$ & Yes & $50 \mathrm{mg}$ & $74.5 \pm 21.6$ \\
\hline$[\mathrm{V}(\mathrm{d})]$ & $50 \mathrm{mg}$ & $8.02 \pm 1.34$ & Yes & $50 \mathrm{mg}$ & $142.6 \pm 13.4$ \\
\hline$[\mathrm{V}(\mathrm{e})]$ & $50 \mathrm{mg}$ & $13.82 \pm 1.71$ & Yes & $50 \mathrm{mg}$ & $132 \pm 13.4$ \\
\hline$[\mathrm{V}(\mathrm{f})]$ & $50 \mathrm{mg}$ & $12.08 \pm 1.11$ & Yes & $50 \mathrm{mg}$ & $70.8 \pm 20.9$ \\
\hline$[\mathrm{V}(\mathrm{g})]$ & $50 \mathrm{mg}$ & $8.78 \pm 1.72$ & Yes & $50 \mathrm{mg}$ & $122.7 \pm 18.4$ \\
\hline$[\mathrm{V}(\mathrm{h})]$ & $50 \mathrm{mg}$ & $12.44 \pm 1.42$ & Yes & $50 \mathrm{mg}$ & $85.6 \pm 16.1$ \\
\hline$[\mathrm{V}(\mathrm{i})]$ & $50 \mathrm{mg}$ & $13.04 \pm 1.22$ & Yes & $50 \mathrm{mg}$ & $78.6 \pm 12.4$ \\
\hline$[V(j)]$ & $50 \mathrm{mg}$ & $9.72 \pm 0.94$ & Yes & $50 \mathrm{mg}$ & $96.6 \pm 25.1$ \\
\hline Phenytoin & $5 \mathrm{mg}$ & $7.62 \pm 1.35$ & Yes & $5 \mathrm{mg}$ & $177.2 \pm 26.6$ \\
\hline Control (saline) & $2 \mathrm{ml}$ & $19.41 \pm 1.32$ & Yes & $2 \mathrm{ml}$ & $129.0 \pm 24.4$ \\
\hline
\end{tabular}

a'Statistical criteria's adopted: $\mathrm{P}<0.01$; one way ANOVA followed by Dunnet's t-test.

\section{RESULT AND DISCUSSION}

All the compounds were screened for their anticonvulsant potential through MES model at dose of $50 \mathrm{mg} / \mathrm{kg}$ by intraperitoneal (i.p.) injection. The data indicates that all the compounds were active in the MES screening (Table II).

The compound [VI(d)] was found to be the most potent among all the synthesized compounds with lesser neurotoxicity. In general, compounds bearing the groups like nitro, hydroxy on distant phenyl ring showed high potency in MES test. The replacement of these groups with methyl groups on the distant phenyl ring has resulted in compounds with decrease in anticonvulsant activity. Replacement of the proton on the carbimino carbon atom by methyl group i.e., compound $[\mathrm{VI}(\mathrm{h})]$ has demonstrated variation in activity due to increase in the dimension of the group at this position of the molecule.

The present studies on title compounds were performed while keeping in mind that a number of clinically active anticonvulsants possess a nitrogen hetero atomic system with one or two phenyl rings and at least one carbonyl group in their structure. The structure of the title compounds 
accomplished all the pharmacophore structural requirements. In the present study, 1-(3-nitrobenzylidene-4-(4-(2-oxoindoline-3ylideneamino)p henyl)semicarazinde $[\mathrm{VI}(\mathrm{d})]$ came out as the most active compound, showing considerable activity in maximal electroshock seizure model with minimum neurotoxicity. The results attained showed that the most of the benzimidazole based semicarbazones showed anticonvulsant activity. Thus, the results validated that four pharmacophore elements in semicarbazones are crucial for their antiepileptic activity.

\section{CONCLUSION}

A series of novel benzimidazole substituted semicarbazones containing 1,3,4-oxadiazole nucleus were synthesized to accomplish the structural prerequisite vital for antiepileptic activity. The structure activity relationship studies represent that anticonvulsant activity changes on differing $p$-substituted group on aryl moiety in the following manner: nitro $>$ hydroxy $>$ chloro $>$ methoxy group. While anticonvulsant activity changes on varying the substitution attached to carbimino carbon atom as follows: $\mathrm{CH}_{3}>\mathrm{H}$. Our results supported that the pharmacophore model with four structural features is imperative for anticonvulsant activity. These new data might be advantageous in the future design and development of semicarbazones as novel anticonvulsants.

\section{ACKNOWLEDGMENT}

The help rendered by SAIF, CDRI Lucknow for elemental and spectral analysis is gratefully acknowledged.

\section{REFERENCES}

[1] R. Fisher, W. V. E. Boas, W. Blume, C. Elger, P. Genton, P. Lee, and J. Engel, "Epileptic seizures and epilepsy: definitions proposed by the International League Against Epilepsy (ILAE) and the International Bureau for Epilepsy (IBE)," Epilepsia, vol. 46, pp. 470-472, Apr. 2005.

[2] T. R. Brown and G. L. Holmes, "Primary care: epilepsy," N. Engl. J. Med., vol. 344, pp. 1145-1151, Apr. 2001.

[3] H. Rajak, B. S. Thakur, A. Singh, K. Raghuvanshi, A. K. Sah, R. Veerasamy, P. C. Sharma, R. S. Pawar, and M. D. Kharya, "Novel limonene and citral based 2,5-disubstituted-1,3,4-oxadiazoles: A natural product coupled approach to semicarbazones for antiepileptic activity," Bioorg. Med. Chem. Lett., vol. 23, pp. 864-868, Feb. 2013.

[4] H. Rajak, P. K. Singour, M. D. Kharya, and P. Mishra, "A novel series of 2,5-disubstituted 1,3,4-oxadiazoles: synthesis and SAR studies for their anticonvulsant activity," Chem. Biol. Drug Des., vol. 77, pp. 152-158, Feb. 2011.

[5] H. Rajak, C. K. Behera, R. S. Pawar, P. K. Singour, and M. D. Kharya, "A novel series of 2,5-disubstituted 1,3,4-thiadiazoles as potential anticonvulsant agent," Chin. Chem. Lett., vol. 21, pp. 1149-1152, Oct. 2010.

[6] M. G. Wong, J. A. Dejina, and P. R. Andrews, "Conformational analysis of clinically active anticonvulsant drugs," J. Med. Chem., vol. 29, pp. 562-571, April 1986.

[7] H. Rajak, R. Deshmukh, R. Veerasamy, A. K. Sharma, P. Mishra, and M. D. Kharya, "Novel semicarbazones based 2,5-disubstituted-1,3,4-oxadiazoles: one more step towards establishing four binding site pharmacophoric model hypothesis for anticonvulsant activity," Bioorg. Med. Chem. Lett., vol. 20, pp. 4168-4172, July 2010.

[8] C. R. Prakash, S. Raja, and G. Saravanan, "Synthesis, characterization and anticonvulant activity of novel Schiff base of isatin derivatives," Int. J. Phar. Pharm. Sci., vol. 2, pp. 177-181, Oct. 2010.

[9] R. L. Krall, J. K. Penry, B. G. White, H. J. Kupferberg, and E. A. Swinyard, "Anticonvulsant drug development: anticonvulsant drug screening," Epilepsia, vol. 19, pp. 409-428, Aug. 1978.

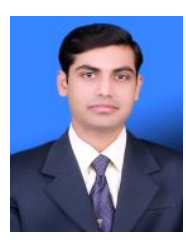

Harish Rajak is an assistant professor of pharmaceutical medicinal chemistry at SLT Institute of Pharmaceutica Sciences, Guru Ghasidas University, Bilaspur (CG) India. $\mathrm{He}$ was born in the year 1978 at Sagar, India. He completed his bachelor, master and doctorate degrees in pharmaceutical sciences in the year 2001, 2003 and 2008, respectively in the field of pharmaceutical sciences from Dr. H S. Gour Univesity, Sagar (MP) India. His current research interest resides in synthesis and biological evaluation of small heterocyclic molecules i.e., histone deacetylase inhibitors and semicarbazones for their anticancer and anticonvulsant activity, respectively. He has research experience of more than 10 years. He has published 45 peer-reviewed articles in international scientific journals with four books including one on "Four Binding Site Hypothesis for Anticonvulsant Activity". He is dealing with several research projects funded by Government of India (UGC \& AICTE) worth more than $\$ 200000$. $\mathrm{He}$ is life member of more than 8 professional bodies including "Indian Science Congress Association", "Institutions of Chemists", and "Society for Biological Chemists". He has presented his research work in more than 20 national and international conferences. 